\title{
Thymoquinone exerts anti-tumor activities on human hepatocellular carcinoma cells: role of angiogenesis-related genes VCAN, Grb2 and $E Z H 2$
}

\author{
Mohammed Y. Alhassania, Samir F. Zohnya,b, Ryan A. Sheikha, Mohammed A. Hassan a,c, \\ Abdulaziz A. Kalantana, Salman Hosawia and Mahmoud Alhosina,d, \\ ${ }^{a}$ Biochemistry Department, Faculty of Science, King Abdulaziz University, Jeddah 21589, Kingdom of Saudi Arabia. \\ ${ }^{b}$ Biochemistry Department, Faculty of Science, Ain Shams University, Abbassia 11566, Cairo, Egypt. \\ ${ }^{c}$ Department of Basic Medical Sciences, College of Medicine and Health Sciences, Hadhramout University, Mukalla, Yemen. \\ ${ }^{a}$ Cancer Metabolism and Epigenetic Unit, Faculty of Science, King Abdulaziz University, Jeddah 21589, Kingdom of Saudi Arabia.
}

Received: 05 April 2019 / Revised: 17 May 2019 / Accepted: 28 May 2019

\begin{abstract}
Human hepatocellular carcinoma (HCC) is the most prevalent and recurrent type of primary adult liver cancer without any effective therapy. Thus, there is an increase demands for finding new drugs and treatment strategies with selective and potent effects towards HCC. Plant-derived compounds acting as anti-cancer agents can induce apoptosis through targeting several signaling pathways. Thymoquinone (TQ), the major biologically active compound of the black seed oil (Nigella sativa) has demonstrated inhibitory activities on various cancers by targeting several pathways. In the present study, we have evaluated the molecular mechanisms that underlie the antiproliferative, anti-metastatic, and pro-apoptotic activities exerted by TQ on liver cancer cell lineHepG2, a well-documented HCC in vitro model. Cell proliferation was determined by WST-1 assay, apoptosis rate was assessed by flow cytometry using annexin-V/7AAD staining, wound healing assay to investigate the metastasis, and the expression of target genes was assessed by Real-time RT-PCR analysis. We found that TQ significantly reduced HepG2 cell viability and induced apoptosis in a dose-dependent manner. Migration of HepG2 cells was suppressed in response to TQ. Moreover, TQ decreased the expression of several angiogenesis-related genes including versican (VCAN), growth factor receptor-bound protein 2 (Grb2), and the histone methyltransferase for lysine 27 of histone 3 (EZH2). The findings suggest that TQ exerts inhibitory effects on HCC most likely through targeting key genes involved in the invasiveness and metastatic activities of HCC cells and also suggest that TQ could be used in future as potential anti-HCC candidate in chemotherapy.
\end{abstract}

Keywords: Thymoquinone, Angiogenesis, Apoptosis, HepG2, Human hepatocellular carcinoma.

(C) Euraass 2019. All rights reserved.

\section{Introduction}

Hepatocellular carcinoma ( $\mathrm{HCC})$ is considered as the predominant form of primary malignant liver tumor and accounts to $80-90 \%$ of all liver cancers [1-3]. Worldwide, HCC accounts to $5 \%$ of all human cancers and approximately one million cases of HCC are

* Corresponding author. E-mail address: malhaseen@kau.edu.sa (M. Alhosin); Ph: +966 597959354

Available online: 30 June 2019

DOI: https://doi.org/10.34154/2019-EJCS-0101-10-16/euraass

Cite this: Eur. J. Cell Sci. 2019, 1(1), 10 - 16.

ISSN-E: 2679-3350.

(C) European Academy of Applied and Social Sciences. Euraass - 2019. All rights reserved. 
diagnosed, while more than $690,000 \mathrm{HCC}$ patients die every year $[4,5]$. Among tumors, HCC is the fifth most common type of cancer in men and eighth in women [6] and is also considered as the third cause which leads to cancer-related death globally [7]. HCC incidence is increasing dramatically in many countries due to the exposure to various environmental risk factors including chronic hepatitis $\mathrm{B}$ and $\mathrm{C}$ viral infections, obesity, and diabetes mellitus [810]. Most HCC cases are diagnosed at late stages where treatments become ineffective [11-13]. At the molecular level, HCC is a complex disease which is a major challenge facing the development of effective treatments [14-16]. Several molecular signaling mechanisms are involved in the development of liver cancer. Indeed, several studies have shown the contribution of multiple pathways in promoting the overexpression of various genes implicated in angiogenesis such as versican (VCAN), growth factor receptor-bound protein 2 (Grb2) and the histone methyltransferase for lysine 27 of histone 3 (EZH2) [5, 17, 18]. A cytoplasmic expression of VCAN protein was shown to be upregulated in HCC compared to matched normal tissues [19] and this overexpression was suggested as candidate biomarker for early stages of HCC [20]. In the same context, high expression of $E Z H 2$ [21] and Grb2 genes [22] were detected in HCC and also suggested as a promising diagnostic biomarkers of HCC.

The current treatment regimens have a number of side effects as well as HCC has low response and resistance to chemotherapy at advanced stages. Therefore, there is an increase need for developing new drugs and treatments with minimum side effects and high potency to treat HCC patients.

The Plant Kingdome is a rich resource for finding treatment for many illnesses and diseases. Many medicinal plants and their purified components such as thymoquinone (TQ) have shown beneficial therapeutic potentials in the recent years, and they are widely used as alternatives to chemical drugs [23]. TQ, the major bioactive component of the essential oil of black seeds (Nigella sativa) has shown promising inhibitory effects of on a large number of tumors including HCC through targeting several pathways [2430]. Several studies investigated the inhibitory effects of $T Q$ on HepG2 cells [31-33] but the underlying molecular mechanisms are still largely unknown [32].

Consequently, the aim of the present study was to evaluate the effect of $T Q$ on the expression of key genes involved in the invasiveness and metastasis of HCC cells. Our results showed that TQ significantly reduced HepG2 cell viability, induced apoptosis and suppressed the migration of HepG2. TQ-induced inhibitory effects in HepG2 were associated with a significant decrease in the expression of several angiogenesis-related genes such as VCAN, Grb2 and EZH2. The present findings suggest that TQ exerts inhibitory effects on HCC most likely through targeting key genes involved in invasion and metastasis, and also suggest that $\mathrm{TQ}$ could be used in future as potential anti-HCC candidate in chemotherapy

\section{Materials and Methods}

\subsection{Cell culture and treatment}

Liver cancer cell lineHepG2 was purchased from American Type Culture Collection, Manassas, VA, USA. Cells were maintained in DMEM (UFC-Biotech, Riyadh, SA) supplemented with 15\% (v/v) fetal bovine serum (BioWhittaker, Lonza, Belgium), penicillin (100 $\mathrm{U} / \mathrm{ml}$ ) and streptomycin $(100 \mu \mathrm{g} / \mathrm{ml})$ (Sigma-Aldrich, St-Louis, MO, USA). Cells were maintained in a humidified incubator containing $5 \% \mathrm{CO}_{2}$ at $37^{\circ} \mathrm{C}$. For all treatments, a $10 \mathrm{mM}$ solution of $\mathrm{TQ}$ (Sigma-Aldrich, St-Louis, MO, USA) was prepared in 10\% DMSO (Sigma-Aldrich, St-Louis, MO, USA) and appropriate working concentrations were prepared with cell culture medium. The final concentration of DMSO was always less than $0.1 \%$ in both control and treated conditions.

\subsection{Cell proliferation assay}

Cell proliferation was analyzed by a colorimetric cell proliferation assay using WST-1 Cell Proliferation Reagent Kit (Sigma-Aldrich, USA). For this purpose, HepG2 cells were seeded in 96-multiwell plates at a density of $10^{4} /$ well and incubated overnight. Then, the cells were exposed to different concentrations of TQ for $24 \mathrm{~h}$. Cell proliferation rate then was evaluated through a rapid WST-1 reagent. $10 \mu \mathrm{L}$ of the WST-1 solution was added and incubated for an additional $3 \mathrm{~h}$ at $37^{\circ} \mathrm{C}$. Finally, the absorbance was read at 450 $\mathrm{nm}$ with a microplate ELISA reader (ELX800 ${ }^{\mathrm{TM}}$ Biotek, USA) and the results were analyzed by the Gen5 software (Biotek, USA). The percentage of cell viability was calculated by assuming control (untreated) samples as $100 \%$ viable.

\subsection{Apoptosis Assay}

To study the apoptosis, HepG2 cells were seeded in 6-well plates at a density of $2 \times 10^{5}$ cells/well, grown for $24 \mathrm{~h}$ and exposed to different concentrations of $\mathrm{TQ}$ for $24 \mathrm{~h}$. Cell apoptosis rate was assessed using the Annexin $\vee$ Binding Guava Nexin® Assay by capillary cytometry (Guava Easycyte Plus HP system, with absolute cell count and six parameters) following the manufacturer's recommendations for adherent cells (Guava Technologies Inc, Hayward, CA, USA). Guava Nexin® Assay utilizes annexin $\mathrm{V}$-phycoerythrin (PE) to detect phosphatidylserine on the external membrane of apoptotic cells. The cell impermeant dye, 7-amino-actinomycin (7-AAD), is used in the Guava Nexin® Assay as an indicator of cell membrane structural integrity.

\subsection{Wound healing assay}

Wound healing assay was described elsewhere [34, 35]. Briefly, The HepG2 cells were seeded in 6-well plate at a density of $2 \times 10^{4}$ cells/well. After an incubation of $24 \mathrm{~h}$, the culture media was removed and a fresh culture media was added with $100 \mu \mathrm{M}$ of TQ 
for $24 \mathrm{~h}$. Then, a scratch was made on the monolayered cells with a $10 \mu \mathrm{l}$ pipette tip in each well. Phase contrast microscope (Leica, Wetzlar, Germany) with 500X magnification was used to record the images at $0 \mathrm{~h}$ and the images of the same scratch were taken after an incubation of $24 \mathrm{~h}$.

\subsection{Real-time RT-PCR analysis}

Real-time RT-PCR analysis was described elsewhere [36]. Briefly, the cells were treated with different concentrations of TQ for $24 \mathrm{~h}$. Total RNA was isolated and purified from HepG2 cells using the RNeasy kit (Qiagen, Hilden, Germany). Then, total RNA was subjected to reverse transcription using oligo dT and Superscript II reverse transcriptase (Invitrogen, Carlsbad, CA, USA). Quantitative real-time PCR was done with the LightCycler 480 SYBR Green I Master kit (Roche Diagnostics) and the Mastercycler Realplex apparatus (Eppendorf, Montesson, France). The results were normalized with RPL11 mRNA. The sequences of the primers for PCR amplification were: VCAN (sense: 5 ' TTGGACTGATGGCAGCACACT-3 '; antisense: 5 , GGCCATTCTCATGCCAAATG -3' ); GRB2 (sense: 5 ' CAGAAGAGAGGCGAGGCTAA- 3 ', antisense: 5 ' AGCTCGTCGTCTGCAGTAG-3 ' ), EZH2 (sense: 5 ' TGTCTTACTTGTGGAGCCGCT -3 ', antisense: 5 ' TGGTGCCAGCAATAGATGCTT-3 ' ), RPL11 (sense: 5 ' AGCCAAGGTCTTGGAGCAGCTTA -3 ', antisense: 5 ' TTGGGCCTCTGACAGTACAGTGAACA -3' ). Amplicons were size controlled on agarose gel and purity was assessed by analysis of the melting curves at the end of the RT-PCR reaction.

\subsection{Statistical Analysis}

All the data were presented as mean \pm SE of triplicates done in the same experiment or an average of at least three separate experiments. The differences between the control and the treated cells were analyzed by Student's t-test (two-tailed) using GraphPad Prism 6 (Graph Pad Software, SanDiego, USA) and the significant differences were indicated as ${ }^{*} p<0.05,{ }^{* *} p<0.01,{ }^{* * *} p<0.001$, ${ }^{* * * *} p<0.0001$.

\section{Results}

\subsection{TQ reduced HepG2 cell viability in a dose-dependent mechanism}

To assess the anti-proliferative effect of TQ in HepG2 cells, cells were incubated with increasing concentrations of TQ for $24 \mathrm{~h}$. We found that TQ significantly inhibited cell proliferation from $10 \mu \mathrm{M}$ compared to the control. Cell proliferation inhibition reached $60 \%$ and $80 \%$ at $30 \mu \mathrm{M}$ and $50 \mu \mathrm{M}$ of TQ respectively (Fig. 1). These findings indicate that $\mathrm{TQ}$ induces a dose-dependent inhibition of HepG2 cell proliferation.

\subsection{TQ induced dose-dependent apoptosis in HepG2 cells}

To investigate the apoptotic effect of TQ in HepG2 cells, cells were exposed to increasing concentrations of TQ for $24 \mathrm{~h}$ (Fig 2). We found that TQ significantly induced early apoptosis at $10 \mu \mathrm{M}$ by $12 \%$, and this percentage reached $42 \%$ and $44 \%$ at $30 \mu \mathrm{M}$ and 50 $\mu \mathrm{M}$ of TQ respectively (Fig. 2B). TQ had no effect on the number of apoptotic cells in late stage and dead cells (Fig. 2C). These findings indicate that $T Q$ induces a dose-dependent early apoptosis in HepG2 cells.

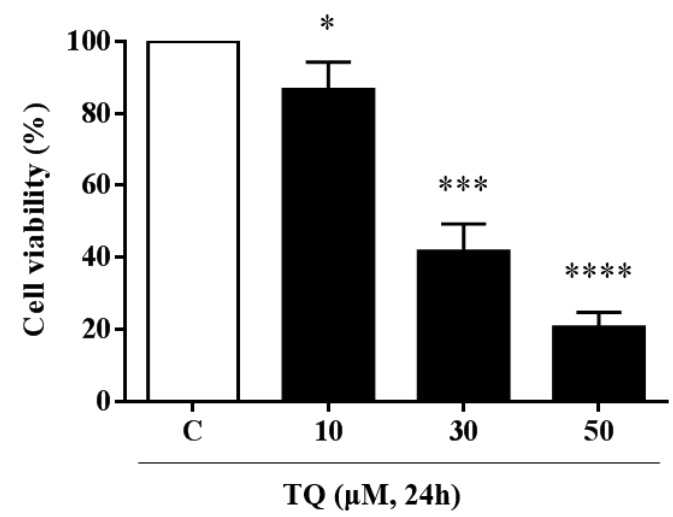

Figure 1: Dose-dependent effects of TQ on HepG2 cell viability. Cells were exposed to increasing concentrations of $T Q$ for $24 \mathrm{~h}$. Cell viability rate was assessed by WST-1 assay. The data are representative of three different experiments $(n=3)$. Values are shown as mean \pm SE. $(n=3)$; ${ }^{*} p<0.05,{ }^{* * *} p<0.001,{ }^{* * *} p<0.0001$ versus respective control.

\subsection{TQ inhibited wound healing in HepG2 cells}

To investigate the effects of $\mathrm{TQ}$ on HepG2 cells motility, we performed a scratch/wound assay. The results displayed an obvious wound at $0 \mathrm{~h}$ that was healed in the control cells after $24 \mathrm{~h}$ (data not shown). Interestingly, the addition of TQ to HepG2 cells at $100 \mu \mathrm{M}$ resulted in a significant inhibition of cellular migration and wound healing (data not shown). These findings indicate TQ has promising potentials in controlling the HepG2 cell migration, and suggest that it could be a potent candidate to regulate metastasis in hepatocellular carcinoma.

\subsection{TQ decreased the expression of the angiogenesis- related genes VCAN, Grb2 and EZH2 in a dose-dependent manner}

As VCAN, Grb2 and EZH2 genes are upregulated in HCC and are known be involved in the angiogenesis, cell proliferation, metastasis and inhibition of apoptosis [5, 17, 18], we studied the effect of TQ at 10, 30 and $50 \mu \mathrm{M}$ TQ for $24 \mathrm{~h}$ on mRNA expression of VCAN (Fig. 3A), Grb2 (Fig. 3B) and EZH2 (Fig. 3C) in HepG2 using RT-qPCR. We found that mRNA expression of all target genes VCAN, Grb2 and EZH2 was significantly decreased in a dose-dependent manner in HepG2 in response to TQ treatment; 
suggesting a significant role for these genes in TQ-induced cell proliferation and metastasis inhibition and apoptosis in HepG2 cells.

(A)

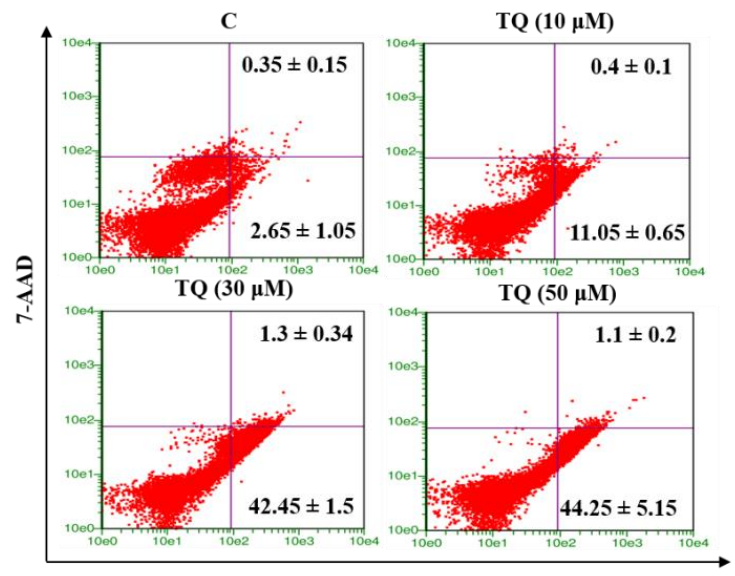

(B)

Annexin V-PE (C)
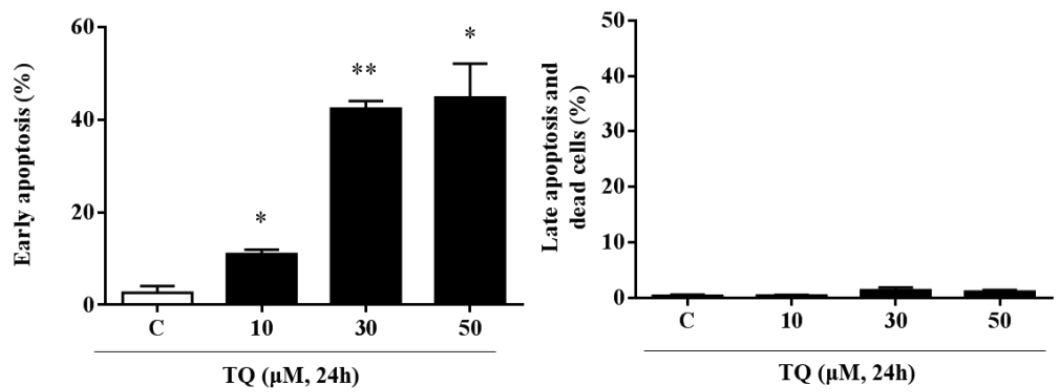

Figure 2: TQ dose effect on apoptosis in HepG2 cells. Cells were exposed to increasing concentrations of TQ for $24 \mathrm{~h}$. Apoptosis in HepG2 cells was assessed by flow cytometry using the annexin V-PE and 7-AAD staining assay. (A) Lower-left quadrant: viable cells (annexin V-PE negative and 7-AAD negative cells). Lower-right quadrant: cells in the early stage of apoptosis (annexin V-PE positive and 7-AAD negative cells). Upper right quadrant: cells in the late apoptotic or dead (annexin V-PE positive and 7-AAD positive cells). Upper-left quadrant: mostly nuclear debris (Annexin VPE negative and 7-AAD positive). The number of apoptotic cells in early stage (B) and late apoptosis and dead cells (C) is expressed as percent relative to the total cell number. Values are shown as mean $\pm \mathrm{SE}(\mathrm{n}=3)$; ${ }^{*} p<0.05$, ${ }^{* *} p<0.01$ versus respective control.

(A)

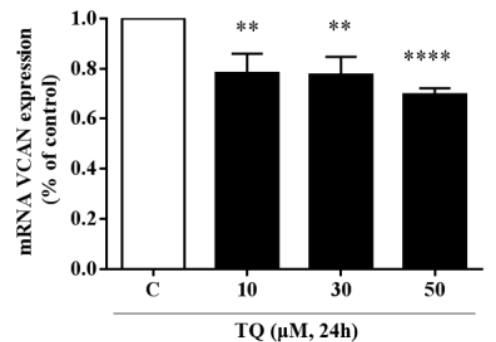

(B)

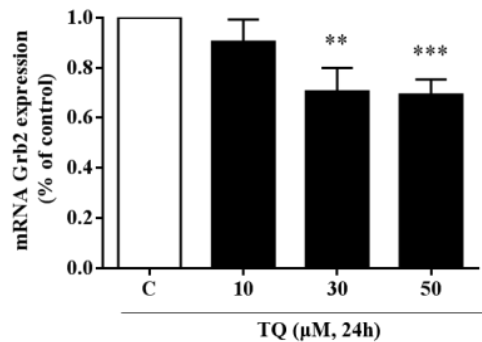

(C)

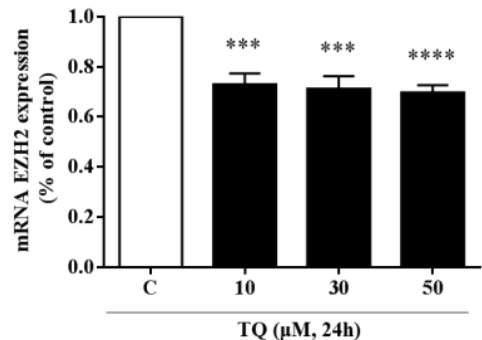

Figure 3: Dose-dependent effects of TQ on the expression of VCAN, Grb2 and EZH2 mRNA levels in HepG2 cells. Cells were exposed to increasing concentrations of TQ for $24 \mathrm{~h}$. The histograms show the quantification data of mRNA expressions of VCAN (A) and Grb2 (B) and EZH2 (C), as assessed by real-time PCR. Results are means of three separate experiments performed in triplicate. Values are shown as means $\pm \mathrm{S} . \mathrm{E} . \mathrm{M}$. $\left(\mathrm{n}=3\right.$ ); ${ }^{\star *} p<0.01,{ }^{\star \star *} p<$ $0.001,{ }^{* * *} p<0.0001$ versus respective control. 


\section{Discussion}

$\mathrm{HCC}$ is one of the most aggressive tumors with high complexity at the molecular level, which represents a major cause that limits the development of effective treatments. Therapies that target angiogenesis-related genes have shown promising results in different cancer therapies. VCAN, Grb2 and EZH2 genes are overexpressed in $\mathrm{HCC}$ and involved in angiogenesis, cell proliferation, metastasis and inhibition of apoptosis. However, due to adverse side effects of current cancer therapies and the resistance to these therapies in advanced stages of HCC cancer, there is an increasing need to find new inhibitors of those genes and other genes that might be involved in cancer progression. In the present study, we have evaluated the molecular mechanisms underlying the anti-proliferative, anti-metastatic and pro-apoptotic activities exerted by $\mathrm{TQ}$ on liver cancer cell line HepG2, a wellestablished HCC model. We found that TQ significantly inhibited HepG2 cell proliferation, migration, and apoptosis in a dose dependent manner; suggesting the specificity of $T Q$ effects since it was used in its pure form. However, how physiological concentrations found naturally in black seeds would correlate with the current findings, and how the variable time points would affect these observations are yet to be tested.

TQ-induced inhibitory effects were also associated with a significant decrease in the expression of VCAN, Grb2 and EZH2 genes in HepG2. High expression levels of VCAN are known to promote proliferation, invasion, and metastasis of a large number of human cancer cells, including HCC [20,37]. The knockdown of VCAN was shown to inhibit glioblastoma cells proliferation and migration most likely through targeting transforming growth factor TGF-beta 2 (TGF- $\beta 2$ ) [38]. Considering the fact that TQ was shown to repress the metastasis of prostate cancer cells through the downregulation of TGF- $\beta$ [39], TQ-induced VCAN downregulation in the present study could be orchestrated by TGF- $\beta$ without excluding other pathways. Additionally, our results showed that $\mathrm{TQ}$ significantly decreased the expression of EZH2 in HepG2 suggesting that $\mathrm{TQ}$ can inhibit $\mathrm{HCC}$ angiogenesis by targeting EZH2. This hypothesis is supported by the fact that EZH2 was shown to has a key role in the regulation of tumor angiogenesis and the decrease in its expression levels inhibited metastasis suggesting $\mathrm{EZH} 2$ as a potential therapeutic target to reverse the migration and invasion of cancer cells [40-44]. Like VCAN and $E Z H 2$ genes, several studies have shown that Grb2 has an important role in proliferation and angiogenesis of several tumors including HCC through its contribution in the signaling pathway of various angiogenic factors $[17,22,45,46]$. The overexpression of miR-564 was shown to inhibit the proliferation, migration and invasion of HCC cell lines through a direct effect on Grb2 gene [46]. In the present study we found that $\mathrm{TQ}$ induces the downregulation of Grb2 in HepG2 with subsequent cell proliferation and metastases inhibition and apoptosis induction indicating that the downregulation of Grb2 is a main event to the inhibition of angiogenesis and induction of apoptosis in HCC in response to natural products. In accordance with this hypothesis, the natural product, sinulariolide has been shown to inhibit HCC cell migration and invasion by suppressing several angiogenic factors including Grb2 [47].

\section{Conclusions}

The present findings indicate that $\mathrm{TQ}$ exerts inhibitory effects on HCC most likely through targeting key genes (VCAN, Grb2 and $E Z H 2)$ involved in the invasiveness and metastasis of HCC cells (Fig. 4). These results also suggest that TQ could be used in future as potential anti-HCC candidate in chemotherapy.

\section{Thymoquinone}

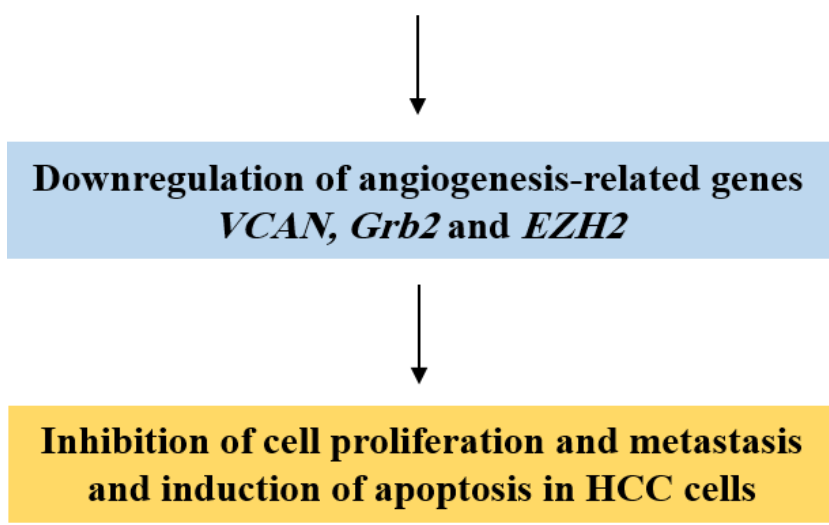

Figure 4: Schematic representation of molecular mechanisms underlie the anti-tumor activities induced by TQ in HCC cells.

\section{Declaration of Conflicting Interests}

The authors declare that they have no financial conflict of interest.

Author Contributions

MA, SFZ and SH designed the project and wrote the paper. MYA, RAS, MAH, and AAK performed research and analyzed data.

\section{References}

1. Zhu RX, Seto WK, Lai CL, Yuen MF: Epidemiology of Hepatocellular Carcinoma in the Asia-Pacific Region. Gut and liver 2016, 10(3):332-339.

2. Sia D, Villanueva A, Friedman SL, Llovet JM: Liver Cancer Cell of Origin, Molecular Class, and Effects on Patient Prognosis. Gastroenterology 2017, 152(4):745-761.

3. Nordenstedt H, White DL, El-Serag HB: The changing pattern of epidemiology in hepatocellular carcinoma. Digestive and liver disease: official journal of the Italian Society of 
Gastroenterology and the Italian Association for the Study of the Liver 2010, 42 Suppl 3:S206-214.

4. Liu J, Wei X, Wu Y, Wang Y, Qiu Y, Shi J, Zhou H, Lu Z, Shao $M, Y u$ L et al: Giganteaside D induces ROS-mediated apoptosis in human hepatocellular carcinoma cells through the MAPK pathway. Cellular oncology (Dordrecht) 2016, 39(4):333342.

5. Costantini S, Di Bernardo G, Cammarota M, Castello G, Colonna G: Gene expression signature of human HepG2 cell line. Gene 2013, 518(2):335-345.

6. Siegel RL, Miller KD, Jemal A: Cancer Statistics, 2017. CA: a cancer journal for clinicians 2017, 67(1):7-30.

7. Lozano R, Naghavi M, Foreman K, Lim S, Shibuya K, Aboyans V, Abraham J, Adair T, Aggarwal R, Ahn SY et al: Global and regional mortality from 235 causes of death for 20 age groups in 1990 and 2010: a systematic analysis for the Global Burden of Disease Study 2010. Lancet (London, England) 2012, 380(9859):2095-2128.

8. Poustchi H, Sepanlou S, Esmaili S, Mehrabi N, Ansarymoghadam A: Hepatocellular carcinoma in the world and the middle East. Middle East journal of digestive diseases 2010, 2(1):31-41.

9. Chitapanarux T, Phornphutkul K: Risk Factors for the Development of Hepatocellular Carcinoma in Thailand. Journal of clinical and translational hepatology 2015, 3(3):182-188.

10. Sanyal AJ, Yoon SK, Lencioni R: The etiology of hepatocellular carcinoma and consequences for treatment. The oncologist 2010, 15 Suppl 4:14-22.

11. El-Serag HB, Davila JA, Petersen NJ, McGlynn KA: The continuing increase in the incidence of hepatocellular carcinoma in the United States: an update. Annals of internal medicine 2003, 139(10):817-823.

12. Llovet JM, Burroughs A, Bruix J: Hepatocellular carcinoma. Lancet (London, England) 2003, 362(9399):1907-1917.

13. Parkin DM, Bray F, Ferlay J, Pisani P: Estimating the world cancer burden: Globocan 2000. International journal of cancer 2001, 94(2):153-156.

14. Dhanasekaran R, Bandoh S, Roberts LR: Molecular pathogenesis of hepatocellular carcinoma and impact of therapeutic advances. F1000Research 2016, 5.

15. Chen C, Wang G: Mechanisms of hepatocellular carcinoma and challenges and opportunities for molecular targeted therapy. World journal of hepatology 2015, 7(15):1964-1970.

16. Brito AF, Abrantes AM, Tralhao JG, Botelho MF: Targeting Hepatocellular Carcinoma: What did we Discover so Far? Oncology reviews 2016, 10(2):302.

17. Soriano JV, Liu N, Gao Y, Yao ZJ, Ishibashi T, Underhill C, Burke TR, Jr., Bottaro DP: Inhibition of angiogenesis by growth factor receptor bound protein 2-Src homology 2 domain bound antagonists. Molecular cancer therapeutics 2004, 3(10):12891299.

18. Lu C, Han HD, Mangala LS, Ali-Fehmi R, Newton CS, Ozbun L, Armaiz-Pena GN, Hu W, Stone RL, Munkarah A et al: Regulation of tumor angiogenesis by EZH2. Cancer cell 2010, 18(2):185-197.

19. Tanaka $Y$, Tateishi $R$, Koike K: Proteoglycans Are Attractive Biomarkers and Therapeutic Targets in Hepatocellular Carcinoma. International journal of molecular sciences 2018, 19(10).

20. Naboulsi W, Megger DA, Bracht T, Kohl M, Turewicz M, Eisenacher M, Voss DM, Schlaak JF, Hoffmann AC, Weber F et al: Quantitative Tissue Proteomics Analysis Reveals Versican as Potential Biomarker for Early-Stage Hepatocellular Carcinoma. Journal of proteome research 2016, 15(1):38-47.

21. Cai MY, Tong ZT, Zheng F, Liao YJ, Wang Y, Rao HL, Chen YC, Wu QL, Liu YH, Guan XY et al: EZH2 protein: a promising immunomarker for the detection of hepatocellular carcinomas in liver needle biopsies. Gut 2011, 60(7):967-976.

22. Zhang Y, Li Z, Yang M, Wang D, Yu L, Guo C, Guo X, Lin N: Identification of GRB2 and GAB1 coexpression as an unfavorable prognostic factor for hepatocellular carcinoma by a combination of expression profile and network analysis. PloS one 2013, 8(12):e85170.

23. Darakhshan S, Bidmeshki Pour A, Hosseinzadeh Colagar A, Sisakhtnezhad S: Thymoquinone and its therapeutic potentials. Pharmacological research 2015, 95-96:138-158.

24. Woo CC, Kumar AP, Sethi G, Tan KH: Thymoquinone: potential cure for inflammatory disorders and cancer. Biochemical pharmacology 2012, 83(4):443-451.

25. Abusnina A, Alhosin M, Keravis T, Muller CD, Fuhrmann G, Bronner C, Lugnier C: Down-regulation of cyclic nucleotide phosphodiesterase PDE1A is the key event of p73 and UHRF1 deregulation in thymoquinone-induced acute lymphoblastic leukemia cell apoptosis. Cell Signal 2011, 23(1):152-160.

26. Alhosin M, Abusnina A, Achour M, Sharif T, Muller C, Peluso J, Chataigneau T, Lugnier C, Schini-Kerth VB, Bronner C et al: Induction of apoptosis by thymoquinone in lymphoblastic leukemia Jurkat cells is mediated by a p73-dependent pathway which targets the epigenetic integrator UHRF1. Biochemical pharmacology 2010, 79(9):1251-1260.

27. Alhosin M, Ibrahim A, Boukhari A, Sharif T, Gies JP, Auger C, Schini-Kerth VB: Anti-neoplastic agent thymoquinone induces degradation of alpha and beta tubulin proteins in human cancer cells without affecting their level in normal human fibroblasts. Investigational new drugs 2012, 30(5):1813-1819.

28. Alhosin M, Sharif T, Mousli M, Etienne-Selloum N, Fuhrmann G, Schini-Kerth VB, Bronner C: Down-regulation of UHRF1, associated with re-expression of tumor suppressor genes, is a common feature of natural compounds exhibiting anti-cancer properties. Journal of experimental \& clinical cancer research: CR 2011, 30:41.

29. Ibrahim A, Alhosin M, Papin C, Ouararhni K, Omran Z, Zamzami MA, Al-Malki AL, Choudhry H, Mely Y, Hamiche A et al: Thymoquinone challenges UHRF1 to commit autoubiquitination: a key event for apoptosis induction in cancer cells. Oncotarget 2018, 9(47):28599-28611.

30. Qadi SA, Hassan MA, Sheikh RA, Baothman OAS, Zamzami MA, Choudhry $\mathrm{H}$, Al-Malki AL, Albukhari A, Alhosin M: Thymoquinone-Induced Reactivation of Tumor Suppressor Genes in Cancer Cells Involves Epigenetic Mechanisms. Epigenetics insights 2019, 12:2516865719839011.

31. ElKhoely A, Hafez HF, Ashmawy AM, Badary O, Abdelaziz A, Mostafa A, Shouman SA: Chemopreventive and therapeutic potentials of thymoquinone in HepG2 cells: mechanistic perspectives. Journal of natural medicines 2015, 69(3):313323.

32. Bimonte S, Albino V, Barbieri A, Tamma ML, Nasto A, Palaia R, Molino C, Bianco P, Vitale A, Schiano R et al: Dissecting the roles of thymoquinone on the prevention and the treatment of hepatocellular carcinoma: an overview on the current state of knowledge. Infectious agents and cancer 2019, 14:10.

33. Ashour AE, Abd-Allah AR, Korashy HM, Attia SM, Alzahrani AZ, Saquib Q, Bakheet SA, Abdel-Hamied HE, Jamal S, Rishi AK: Thymoquinone suppression of the human hepatocellular carcinoma cell growth involves inhibition of IL-8 expression, elevated levels of TRAIL receptors, oxidative stress and apoptosis. Molecular and cellular biochemistry 2014, 389(12):85-98

34. Al-Malki AL, Razvi SS, Mohammed FA, Zamzami MA, Choudhry H, Kumosani TA, Balamash KS, Alshubaily FA, SA $\mathrm{AL}$, Abualnaja KO et al: Synthesis and in vitro antitumor activity of novel acylspermidine derivative $\mathrm{N}$-(4-aminobutyl)- $\mathrm{N}-(3-$ aminopropyl)-8-hydroxy-dodecanamide (AAHD) against HepG2 cells. Bioorganic chemistry 2019, 88:102937. 
35. Hasan MN, Choudhry H, Razvi SS, Moselhy SS, Kumosani TA, Zamzami MA, Omran Z, Halwani MA, Al-Babili S, Abualnaja $\mathrm{KO}$ et al: Synthetic strigolactone analogues reveal anti-cancer activities on hepatocellular carcinoma cells. Bioorganic \& medicinal chemistry letters 2018, 28(6):1077-1083.

36. Achour $M$, Jacq $X$, Ronde $P$, Alhosin $M$, Charlot $C$, Chataigneau $T$, Jeanblanc $M$, Macaluso $M$, Giordano $A$, Hughes AD et al: The interaction of the SRA domain of ICBP90 with a novel domain of DNMT1 is involved in the regulation of VEGF gene expression. Oncogene 2008, 27(15):2187-2197.

37. Liu X, Han C, Liao X, Yu L, Zhu G, Su H, Qin W, Lu S, Ye X, Peng $T$ : Genetic variants in the exon region of versican predict survival of patients with resected early-stage hepatitis B virusassociated hepatocellular carcinoma. Cancer management and research 2018, 10:1027-1036.

38. Onken J, Moeckel S, Leukel P, Leidgens V, Baumann F, Bogdahn U, Vollmann-Zwerenz A, Hau P: Versican isoform V1 regulates proliferation and migration in high-grade gliomas. Journal of neuro-oncology 2014, 120(1):73-83.

39. Kou B, Liu W, Zhao W, Duan P, Yang Y, Yi Q, Guo F, Li J, Zhou J, Kou Q: Thymoquinone inhibits epithelial-mesenchymal transition in prostate cancer cells by negatively regulating the TGF-beta/Smad2/3 signaling pathway. Oncology reports 2017, 38(6):3592-3598.

40. He M, Zhang W, Bakken T, Schutten M, Toth Z, Jung JU, Gill $P$, Cannon M, Gao SJ: Cancer angiogenesis induced by Kaposi sarcoma-associated herpesvirus is mediated by EZH2. Cancer research 2012, 72(14):3582-3592.

41. Smits M, Nilsson J, Mir SE, van der Stoop PM, Hulleman E, Niers JM, de Witt Hamer PC, Marquez VE, Cloos J, Krichevsky $\mathrm{AM}$ et al: miR-101 is down-regulated in glioblastoma resulting in EZH2-induced proliferation, migration, and angiogenesis. Oncotarget 2010, 1(8):710-720.

42. Crea F, Fornaro L, Bocci G, Sun L, Farrar WL, Falcone A, Danesi R: EZH2 inhibition: targeting the crossroad of tumor invasion and angiogenesis. Cancer metastasis reviews 2012, 31(3-4):753-761.

43. Lu J, Zhao FP, Peng Z, Zhang MW, Lin SX, Liang BJ, Zhang B, Liu X, Wang L, Li G et al: EZH2 promotes angiogenesis through inhibition of miR-1/Endothelin-1 axis in nasopharyngeal carcinoma. Oncotarget 2014, 5(22):11319-11332.

44. Liu B, Pang B, Wang Q, Yang S, Gao T, Ding Q, Liu H, Yang $\mathrm{Y}$, Fan $\mathrm{H}$, Zhang $\mathrm{R}$ et al: $\mathrm{EZH} 2$ upregulation correlates with tumor invasiveness, proliferation, and angiogenesis in human pituitary adenomas. Human pathology 2017, 66:101-107.

45. Chen Y, Liu Q, Wu M, Li M, Ding H, Shan X, Liu J, Tao T, Ni R, Chen X: GAB2 promotes cell proliferation by activating the ERK signaling pathway in hepatocellular carcinoma. Tumour biology : the journal of the International Society for Oncodevelopmental Biology and Medicine 2016, 37(9):1176311773.

46. Liang C, Xu Y, Ge H, Xing B, Li G, Li G, Wu J: miR-564 inhibits hepatocellular carcinoma cell proliferation and invasion by targeting the GRB2-ERK1/2-AKT axis. Oncotarget 2017, 8(64):107543-107557.

47. Wu YJ, Neoh CA, Tsao CY, Su JH, Li HH: Sinulariolide Suppresses Human Hepatocellular Carcinoma Cell Migration and Invasion by Inhibiting Matrix Metalloproteinase-2/-9 through MAPKs and PI3K/Akt Signaling Pathways. International journal of molecular sciences 2015, 16(7):1646916482. 